\title{
Análise das Questões do ENEM relativas aos Biomas Brasileiros no Período 2015-2019
}

\author{
Analysis of ENEM questions related to Brazilian Biomes in the \\ 2015-2019 period
Análisis de las preguntas de ENEM relacionadas con los biomas brasileños en el período 2015-2019

Cláudia Rigoli Schneider (claudiarschneider@gmail.com)

Universidade Regional Integrada do Alto Uruguai e das Missões- URI

Neusa Maria John Scheid (scheid.neusa@gmail.com)

Universidade Regional Integrada do Alto Uruguai e das Missões- URI

Noemi Boer (noemiboer@gmail.com)

Universidade Regional Integrada do Alto Uruguai e das Missões- URI

Resumo: Este artigo é decorrente da pesquisa desenvolvida para a dissertação de mestrado da primeira autora e tem por objetivo analisar as questões da prova de Ciências da Natureza e suas Tecnologias, do Exame Nacional do Ensino Médio (ENEM), no período 2015-2019. Considerando-se a extensão do conteúdo, elegeu-se, para análise, as questões relativas aos biomas brasileiros da prova de Biologia e se constatou que, no período analisado, conhecimentos de Ecologia foram frequentes nas provas de Ciências da Natureza e suas Tecnologias, mas questões relacionadas aos biomas brasileiros são praticamente inexistentes. Com base nessa preocupante evidência, pode-se inferir que o tema sobre biomas brasileiros é considerado conteúdo secundário nas avaliações do ENEM, o que pode afetar o ensino de Biologia nas escolas do país, tendo em vista que os conteúdos eleitos no exame são, geralmente, referência ao planejamento didático-pedagógico dos professores.

Palavras-chave: Ensino de biologia; BNCC; Competências e habilidades.

Abstract: This article is due to the research developed to the Masters dissertation of the first author and has as objective to analyse the questions from the Natural Sciences and its Technologies exam on the National High School Exam (ENEM), in the 2015-2019 period. Considering the extant of content in this exam, it was elected for review questions related to Brazilian biomes, presents in the biology test, it was verified that, in the reviewed period, knowledge in Ecology was prioritized in the National Sciences and its Technologies exam, but questions related to Brazilian biomes are practically nonexistent. Based on this worrying evidence, it can be infered that the Brazilian biomes are considered secondary content in the ENEM evaluation, what might interfere in the Biology study in the schools across the country, having in mind that the

Recebido em: 30/05/2021

Aceite em: 13/08/2021 
prioritized contents on the exams are, usually, reference to the didactic-pedagogical planning of the teachers.

Keywords: Biology study; BNCC; Competence and skills.

Resumen: Este artículo deriva de la investigación desarrollada para la tesis de maestría de la primera autora y tiene como objetivo analizar las cuestiones de la prueba de Ciencias Naturales y sus Tecnologías, del Examen Nacional de Secundaria (ENEM), en el período 2015-2019. Considerando la extensión del contenido, se eligieron para el análisis las preguntas relacionadas con los biomas brasileños de la prueba de Biología y se encontró que, en el período analizado, el conocimiento de Ecología fue frecuente en las pruebas de Ciencias Naturales y sus Tecnologías, pero cuestiones relacionadas a los biomas brasileños son prácticamente inexistentes. Con base en esta preocupante evidencia, se puede inferir que el tema de los biomas brasileños se considera contenido secundario en las evaluaciones ENEM, lo que puede afectar la enseñanza de la Biología en las escuelas del país, una vez que los contenidos elegidos en el examen son, en general, referencia para planificación didáctico-pedagógica de los profesores.

Palabras clave: Enseñanza de la biología; BNCC; Habilidades y destrezas.

\section{INTRODUÇÃO}

O Exame Nacional do Ensino Médio (ENEM) foi criado pelo Ministério da Educação (MEC), em 1998, para avaliar o desempenho dos estudantes no final da educação básica. Atualmente, a nota do ENEM serve como referência para o estudante ingressar na universidade e, também, como critério para acesso ao financiamento estudantil e a bolsas de estudo na grande maioria das instituições de ensino superior do país. É considerado um exame de característica classificatória e diagnóstica, que compara e mede resultados, expressando a pontuação dos alunos em faixas de desempenho (ZANCHET, 2003). Nessa perspectiva, durante o Ensino Médio, o estudante é preparado com atividades que explorem competências e habilidades exigidas pelo ENEM, para obtenção de bons resultados no exame.

Segundo o Guia do Estudante, as questões sobre Ecologia e Ciências Ambientais correspondem a $29,6 \%$ de todos os questionamentos sobre Biologia e 9,3\% sobre o conteúdo referente a Ciências da Natureza e suas Tecnologias (ILHÉU, 2019). Neste artigo, investiga-se a frequência com que os conteúdos relacionados aos biomas brasileiros são contemplados nas provas do ENEM, tendo em vista que a primeira 
autora é professora de Biologia no Ensino Médio e demonstra preocupação quanto à tímida relevância dada ao tema.

Acredita-se, nesses termos, que os biomas brasileiros sejam pouco abordados na Educação Básica por conta das dificuldades operacionais que os professores de Ciências e de Biologia têm na contextualização desses temas em sala de aula. Para fundamentar esse argumento, cita-se que o livro didático dedica pouco espaço ao conteúdo, o que, no mínimo, é preocupante, pois os biomas, por abrangerem todo o território nacional, deveriam ser motivo de reflexão constante, mas, ao contrário, são tratados sem a devida importância (BEZERRA; SUESS, 2013; CASTRO et al., 2019). O livro, como recurso didático, exerce certa influência na organização do trabalho pedagógico, seja de forma direta, quando adotado pela escola ou pelo professor, seja de maneira indireta, como material de apoio (XAVIER; SOUZA, 2008).

Com base nessa consideração, nos livros didáticos de Biologia, utilizados em âmbito escolar e aprovados pelo Programa Nacional do Livro Didático (PNLD, 2018), Pigatto e Lopes (2019, p. 01) identificam-se também "discrepâncias tanto em relação ao conceito do termo bioma, quanto em relação à classificação dos biomas brasileiros apresentados nesses livros". Por outro lado, Leopoldo e Bastos (2018, p. 18), declaram que "o livro didático interfere na ação docente, no currículo escolar e nos modos de ensino, devendo ser utilizado como um apoio e não origem do trabalho pedagógico".

Conhecer a fauna e a flora dos biomas brasileiros deve ser prioridade para abordar temáticas em sala de aula, como desmatamento, poluição, extinção de espécies, contrabando de animais silvestres, entre outras. Um bioma pode ser descrito como um conjunto "de vida (vegetal e animal), constituído pelo agrupamento de tipos de vegetação contíguos e identificáveis em escala regional, com condições geoclimáticas similares e história compartilhada de mudanças, o que resulta em uma diversidade biológica própria" (INSTITUTO BRASILEIRO DE GEOGRAFIA E ESTATÍSTICA, 2004, p. 11). Segundo Ab’Sáber (2003), até o momento, foram reconhecidos seis grandes domínios paisagísticos e macroecológicos em nosso país, conhecidos como biomas: Caatinga, Cerrado, Pantanal, Amazônia, Mata Atlântica e o Pampa, descritos no decurso do texto. 
Por conta dessa constatação, objetivou-se analisar as questões do Exame Nacional do Ensino Médio, no período 2015-2019, da prova de Ciências da Natureza e suas Tecnologias, na disciplina de Biologia, para verificar com que frequência o tema sobre biomas brasileiros foi contemplado, como questão, pelo ENEM.

Além desta introdução, o texto está organizado em mais quatro seções. O aporte teórico do estudo encontra-se descrito em duas seções, respectivamente, nomeadas de Considerações relativas ao ENEM e Descrição dos biomas brasileiros. Na terceira seção, descreve-se a metodologia da pesquisa, desenvolvida em três etapas; na quarta, apresentam-se os dados da pesquisa e a respectiva análise. Nas considerações finais, retoma-se o problema e o objetivo de pesquisa para tecer a conclusão do estudo.

\section{EXAME NACIONAL DO ENSINO MÉDIO - ENEM}

Com o objetivo de avaliar o desempenho do estudante ao final da educação básica, o Instituto Nacional de Estudos e Pesquisas (INEP), do Ministério da Educação e Cultura (MEC), criou, em 1998, o Exame Nacional do Ensino Médio (ENEM),

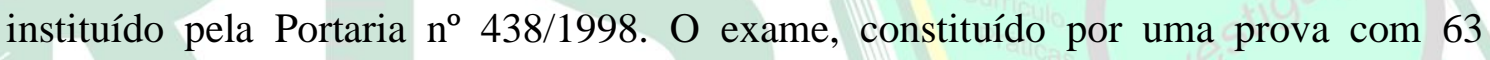
questões objetivas de múltipla escolha e uma proposta de redação, reflete um modelo de avaliação focado nas competências e habilidades construídas durante a educação básica (GOMES, 2010; INEP, 2002; MALIPENSA; RINK, 2017).

Até o ano de 2008, o exame era aplicado exclusivamente para avaliar o desempenho dos concluintes do Ensino Médio, sem a finalidade da seleção para o ensino superior. Em 2009, o Ministério da Educação apresentou uma reformulação do exame, propondo usar a prova como forma de acesso ao ensino superior no Brasil e não apenas para a avaliação do ensino médio. O ENEM, então, passou a ser utilizado como ferramenta de avaliação para ingresso ao ensino superior, pela Portaria 462/2009, do Ministério da Educação (BRASIL, 2009a). Em seu Art. $2^{\circ}$, consta que o Exame Nacional do Ensino Médio - ENEM

se constituirá de uma prova de múltipla escolha de cada área do conhecimento, e uma redação, avaliará as competências e as habilidades desenvolvidas pelos examinandos ao longo do ensino fundamental e médio, imprescindíveis à vida acadêmica, ao mundo do trabalho e ao exercício da cidadania, tendo como base a matriz de competências especialmente definida para o exame (BRASIL, 2009).

Considerado um expressivo indicador da educação brasileira e uma das formas mais democráticas de ingresso ao ensino superior, o ENEM é disponibilizado, anualmente, para alunos de escolas públicas e privadas nas 27 unidades federativas. Pautado nos conhecimentos e habilidades do aluno, o teste tem como diferencial a 
transdisciplinaridade nas questões, cuja proposta é avaliar o estudante pelo raciocínio, interpretação e domínio de todo o conteúdo ministrado no ensino médio. Dessa forma, o ENEM propõe mensurar modalidades estruturais da inteligência, denominadas competências (BRASIL, 1998, 2000, 2001).

Atualmente, reconhecido como o maior teste educacional do Brasil, o ENEM é composto por 180 questões de múltipla escolha, aplicadas em dois dias consecutivos. No ano de 2017, ocorreu a mudança para dois domingos consecutivos. As provas são divididas em quatro áreas de conhecimento: Ciências Humanas e suas Tecnologias (História, Geografia, Filosofia e Sociologia); Ciências da Natureza e suas Tecnologias (Química, Física e Biologia); Linguagens, Códigos e suas Tecnologias (Língua Portuguesa, Literatura, Língua Estrangeira, Artes, Educação Física), Matemática e suas Tecnologias. Os candidatos inscritos no exame também são submetidos a uma prova de redação, do tipo dissertativo-argumentativo, sobre um tema de ordem social, científica, cultural ou política e deve ser produzido em até 30 linhas, seguindo a norma padrão da Língua Portuguesa (BRASIL, 2009).

Para isso, a prova do ENEM tem cinco notas: uma para cada área de conhecimento, Ciências da Natureza, Ciências Humanas, Linguagens e Matemática, mais a média da redação. Para o cálculo das médias em cada uma das quatro áreas, é utilizada a metodologia da Teoria de Resposta ao Item (TRI), que mede o conhecimento a partir do comportamento observado em testes. O exame é usado como critério de seleção para bolsas parciais ou integrais no Programa Universidade para Todos (PROUNI); obtenção de financiamento de graduação pelo Fundo de Financiamento Estudantil (FIES); complemento ou substituição de vestibulares, Sistema de Seleção Unificado (SISU), ou ainda, seleção de cotistas.

Pelo SISU, os estudantes pleiteiam vagas nas universidades públicas, mas o exame também é utilizado como forma de ingresso em universidades privadas, que determinam o próprio peso a cada prova do ENEM. Desse modo, o ENEM, muitas vezes, é um complemento da nota obtida no vestibular ou funciona como uma porcentagem para completar a nota obtida na prova convencional, que varia de universidade para universidade, ou seja, pode ser considerada uma parte do processo seletivo, $50 \%$ da prova, ou um auxílio para aumentar a nota do vestibular. O conteúdo 
das provas do Enem é definido a partir de matrizes de referência em quatro áreas do conhecimento, conforme acima apresentado.

A partir de 2009, o ENEM assumiu um novo formato e as provas objetivas e a redação foram baseadas em uma matriz de competências, relacionada à capacidade de $\mathrm{o}$ estudante resolver problemas, analisar fenômenos da natureza, dominar a norma culta da língua portuguesa e elaborar propostas para questões sociais. Para cada domínio, existe um conjunto de habilidades que o estudante deve possuir para demonstrar essa prática quanto às competências. A Matriz de Referência de Ciências da NaturezaBiologia cita, como objetos do conhecimento: Moléculas, células e tecidos, Hereditariedade e diversidade da vida, Identidade dos seres vivos, Ecologia e ciências ambientais, Origem e evolução da vida e Qualidade de vida das populações humanas (INEP, 2020).

A Matriz de referência quanto às competências e habilidades em Ciências da Natureza encontra-se sistematizada no Quadro 1, a seguir.

Quadro 1. Síntese das competências e habilidades, segundo a matriz de referência de Ciências da Natureza e suas Tecnologias do ENEM

\section{Competências das Áreas $\quad$ Caracterização das competências e habilidades}

Competência da área 1 - $\mathrm{H} 1$ - Reconhecer características ou propriedades de Compreender as ciências fenômenos ondulatórios ou oscilatórios, naturais e as tecnologias a relacionando-os a seus usos em diferentes contextos. elas associadas, como construções humanas, percebendo seus papéis nos processos de produção e no desenvolvimento econômico e social da humanidade. H2 - Associar a solução de problemas de comunicação, transporte, saúde ou outro, com o correspondente desenvolvimento científico e tecnológico.

H3 - Confrontar interpretações científicas com interpretações baseadas no senso comum, ao longo do tempo ou em diferentes culturas.

H4 - Avaliar propostas de intervenção no ambiente, considerando a qualidade da vida humana ou medidas de conservação, recuperação ou utilização sustentável da biodiversidade.

Competência da área 2 - H5 - Dimensionar circuitos ou dispositivos elétricos Identificar e aplicar as de uso cotidiano.

tecnologias associadas às H6 - Relacionar informações para compreender Ciências Naturais em manuais de instalação ou utilização de aparelhos ou diferentes contextos. sistemas tecnológicos de uso comum. H7 - Selecionar testes de controle, parâmetros ou critérios para a comparação de materiais e produtos, 


\section{Competência da área 3 -}

Associar intervenções que resultam degradação ou conservação ambiental a processos produtivos e sociais e a instrumentos ou ações científico-tecnológicas.

\section{Competência da área 4 -} Compreender interações entre organismos e ambiente, em particular, aquelas relacionadas à saúde humana, vinculando conhecimentos científicos, aspectos culturais e características individuais.

\section{Competência da área 5 -}

Entender métodos procedimentos próprios das Ciências Naturais e aplicá-los em diferentes contextos. tendo em vista a defesa do consumidor, a saúde do trabalhador ou a qualidade de vida.

H8 - Identificar etapas em processos de obtenção, transformação, utilização ou reciclagem de recursos naturais, energéticos ou matérias-primas, considerando processos biológicos, químicos ou físicos neles envolvidos.

H9 - Compreender a importância dos ciclos biogeoquímicos ou do fluxo energia para a vida ou da ação de agentes ou fenômenos que podem causar alterações nesses processos.

H10 - Analisar perturbações ambientais, identificando fontes, transporte $\mathrm{e}(\mathrm{ou})$ destino dos poluentes, prevendo efeitos em sistemas naturais, produtivos ou sociais.

H11 - Reconhecer benefícios, limitações e aspectos éticos da biotecnologia, considerando estruturas e processos biológicos envolvidos em produtos biotecnológicos.

H12 - Avaliar impactos em ambientes naturais, decorrentes de atividades sociais ou econômicas, considerando interesses contraditórios.

H13 - Reconhecer mecanismos de transmissão da vida, prevendo ou explicando a manifestação de características dos seres vivos.

H14 - Identificar padrões em fenômenos e processos vitais dos organismos, como manutenção do equilíbrio interno, defesa, relações com o ambiente, sexualidade, entre outros.

H15 - Interpretar modelos e experimentos para explicar fenômenos ou processos biológicos em qualquer nível de organização dos sistemas biológicos.

H16 - Compreender o papel da evolução na produção de padrões, processos biológicos ou na organização taxonômica dos seres vivos.

H17 - Relacionar informações apresentadas em diferentes formas de linguagem e representação, usadas nas ciências físicas, químicas ou biológicas, como texto discursivo, gráficos, tabelas, relações matemáticas ou linguagem simbólica.

H18 - Relacionar propriedades físicas, químicas ou biológicas de produtos, sistemas ou procedimentos tecnológicos às finalidades a que se destinam.

H19 - Avaliar métodos, processos ou procedimentos das Ciências Naturais que contribuam para diagnosticar ou solucionar problemas de ordem social, econômica ou ambiental. 
Competência da área $6-\mid \mathrm{H} 20$ - Caracterizar causas ou efeitos dos movimentos Apropriar-se

de de partículas, substâncias, objetos ou corpos celestes. conhecimentos da Física para, em situações-problema, interpretar, avaliar ou planejar intervenções científico- tecnológicas.

H21 - Utilizar leis físicas e (ou) químicas para interpretar processos naturais ou tecnológicos, inseridos no contexto da termodinâmica e(ou) do eletromagnetismo.

H22 - Compreender fenômenos decorrentes da interação entre a radiação e a matéria em suas manifestações em processos naturais ou tecnológicos, ou em suas implicações biológicas, sociais, econômicas ou ambientais.

H23 - Avaliar possibilidades de geração, uso ou transformação de energia em ambientes específicos, considerando implicações éticas, ambientais, sociais e/ou econômicas.

Competência da área 7 Apropriar-se conhecimentos da Química para, em situações- problema, interpretar, avaliar ou planejar intervenções científico- tecnológicas.

H24 - Utilizar códigos e nomenclatura da Química para caracterizar materiais, substâncias ou transformações químicas.

H25 - Caracterizar materiais ou substâncias, identificando etapas, rendimentos ou implicações biológicas, sociais, econômicas ou ambientais de sua obtenção ou produção.

H26 - Avaliar implicações sociais, ambientais e/ou econômicas na produção ou no consumo de recursos energéticos ou minerais, identificando transformações químicas ou de energia, envolvidas nesses processos.

H27 - Avaliar propostas de intervenção no meio ambiente, aplicar conhecimentos químicos, observando riscos ou benefícios.

Competência da área 8 - H28 - Associar características adaptativas dos Apropriar-se de conhecimentos da Biologia para, em situações- problema, interpretar, avaliar ou planejar intervenções científico- tecnológicas. organismos com seu modo de vida ou com seus limites de distribuição em diferentes ambientes, em especial, em ambientes brasileiros.

H29 - Interpretar experimentos ou técnicas que utilizam seres vivos, analisando implicações para o ambiente, a saúde, a produção de alimentos, matérias primas ou produtos industriais.

H30 - Avaliar propostas de alcance individual ou coletivo, identificando aquelas que visam à preservação e à implementação da saúde individual, coletiva ou do ambiente.

Fonte: Adaptado do INEP, 2020

A partir de 17 de dezembro de 2018, a Resolução CNE/CP, n 4, institui a Base Nacional Comum Curricular na Etapa do Ensino Médio (BNCC-EM), como etapa final da Educação Básica, nos termos do artigo 35, da LDB, completando o conjunto 
constituído pela BNCC da Educação Infantil e do Ensino Fundamental, com base na Resolução CNE/CP, no 2/2017, fundamentada no Parecer CNE/CP, no 15/2017 (BRASIL, 2018).

A BNCC define os direitos de aprendizagem de todos os alunos do Brasil e norteia os conhecimentos essenciais que todos os estudantes devem aprender para desenvolver as habilidades e competências ao longo da sua vida escolar. Esse documento vem ao encontro do ENEM para padronizar a educação no Brasil, com a finalidade de garantir a igualdade, diversidade e equidade a todos os alunos.

Com esse propósito, a BNCC do Ensino Médio está organizada por áreas de conhecimento: Linguagens e suas Tecnologias, Matemática e suas Tecnologias, Ciências da Natureza e suas Tecnologias, Ciências Humanas e Sociais Aplicadas. Na BNCC, são definidas competências específicas para cada área do conhecimento, relacionando-as às habilidades necessárias na formação do estudante. Segundo a BNCC, a área de Ciências da Natureza deve

se comprometer com a formação dos jovens para o enfrentamento dos desafios da contemporaneidade e ensinar aos alunos a interpretação de fenômenos naturais e processos tecnológicos de modo a possibilitar aos estudantes a apropriação de conceitos, procedimentos e teorias dos diversos campos das Ciências da Natureza (BRASIL, 2018, p. 537).

Segundo Silva et al. (2020), os professores brasileiros acreditam que o ENEM promoveu mudanças na organização curricular e na prática pedagógica. Mesmo que as escolas não tenham o currículo definido pela matriz do ENEM, todos os professores trabalham algumas questões dos exames em suas disciplinas. Como o Exame Nacional do Ensino Médio passou a ser utilizado como ferramenta de avaliação para ingresso ao Ensino Superior, existe uma grande preocupação em preparar os alunos para o exame, pois, para muitos, será a única possibilidade de acesso à universidade.

\section{BIOMAS BRASILEIROS}

Os biomas brasileiros compreendem toda a diversidade de fauna e flora do país. Lamentavelmente, sua conservação está cada vez mais ameaçada por atividades antrópicas, principalmente aquelas ligadas à conversão das paisagens naturais em áreas de produção agropecuária e ocupação imobiliária (ALEIXO et al., 2010). Além das ações antrópicas, o clima também está ameaçando a continuidade desses ecossistemas. Isso se deve, principalmente, pelo crescimento populacional e pela falta de políticas públicas voltadas à sua preservação.

Recebido em: 30/05/2021

Aceite em: 13/08/2021 
De acordo com Ab’Sáber (2003, p. 13):

\begin{abstract}
Até o momento foram reconhecidos seis grandes domínios paisagísticos e macroecológicos em nosso país. Quatro deles são intertropicais, cobrindo uma área pouco superior a sete milhões de quilômetros quadrados. Os dois outros são subtropicais, constituindo aproximadamente 500 mil quilômetros em território brasileiro, posto que extravasando para áreas vizinhas dos países platinos.
\end{abstract}

Esses dados são corroborados pelo IBGE (2004) ao declarar que existem, no Brasil, seis grandes biomas, denominados Caatinga, Cerrado, Pantanal, Amazônia, Mata Atlântica e Pampa, identificados na Figura 1, a seguir.

Figura 1: Demonstrativo dos biomas no mapa do Brasil, IBGE, 2004.

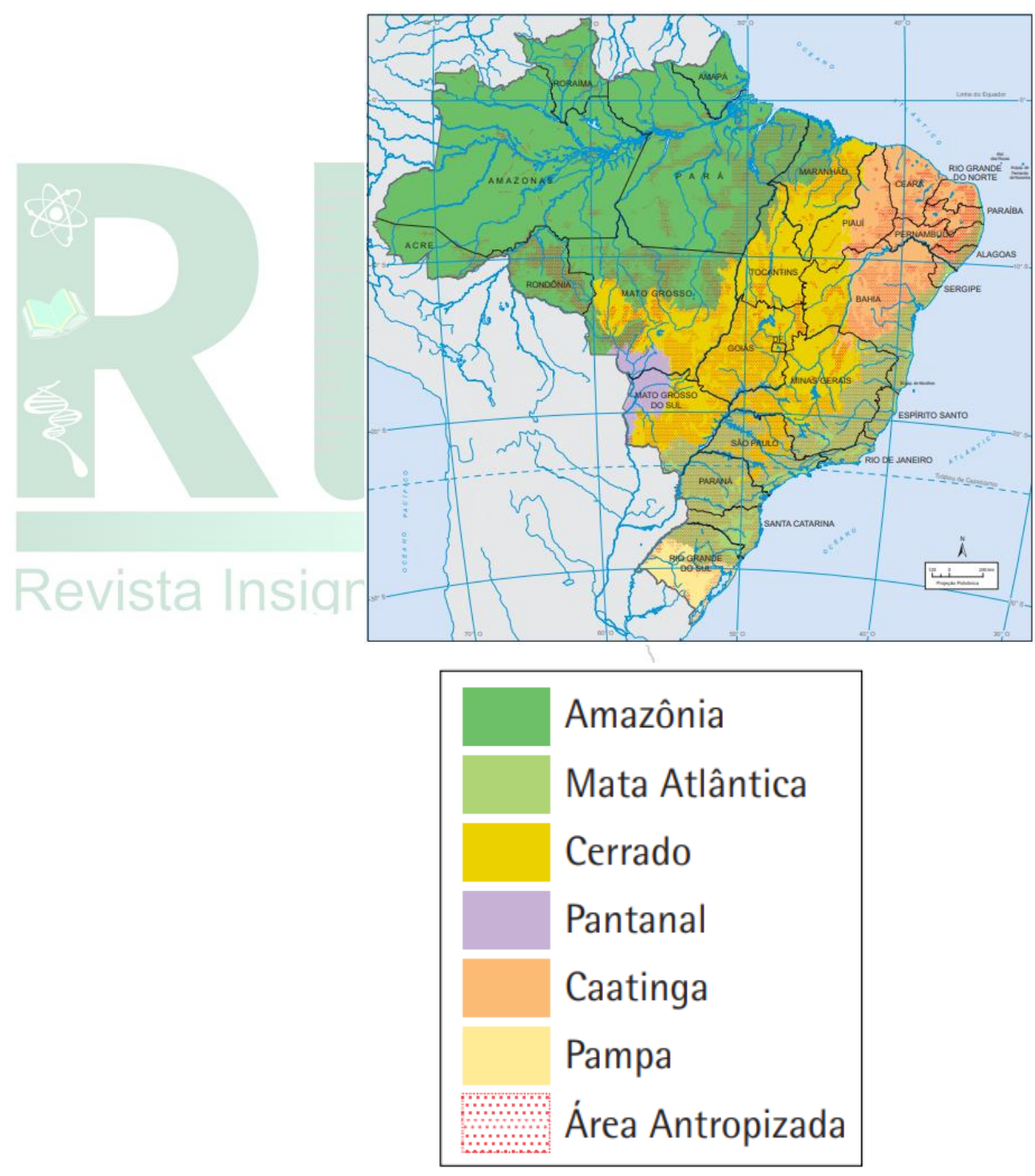

Fonte: Autores (2020)

A descrição dos seis biomas brasileiros encontra-se sintetizada no Quadro 2, abaixo.

Recebido em: 30/05/2021

Aceite em: 13/08/2021 
Quadro 2. Síntese dos seis biomas brasileiros, segundo o IBGE 2004.

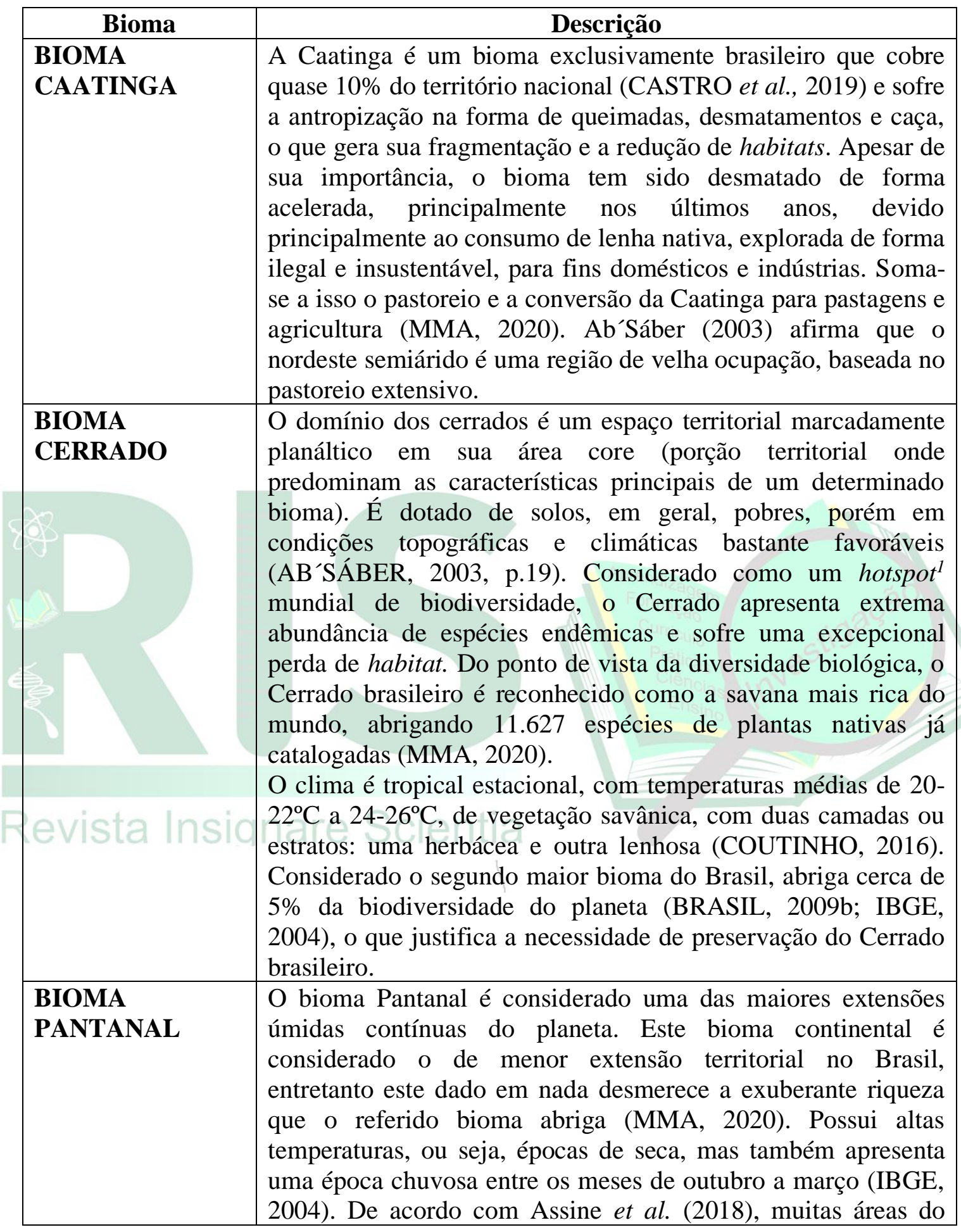

${ }^{1}$ Hotspots - áreas em florestas tropicais que se enquadrem em dois requisitos:

“a) Apresentem uma concentração de espécies excepcional com níveis de endemismo excepcionais e que

b) Estejam diante de graus de ameaça excepcionais" (MYERS, 1988).

Recebido em: 30/05/2021

Aceite em: 13/08/2021 


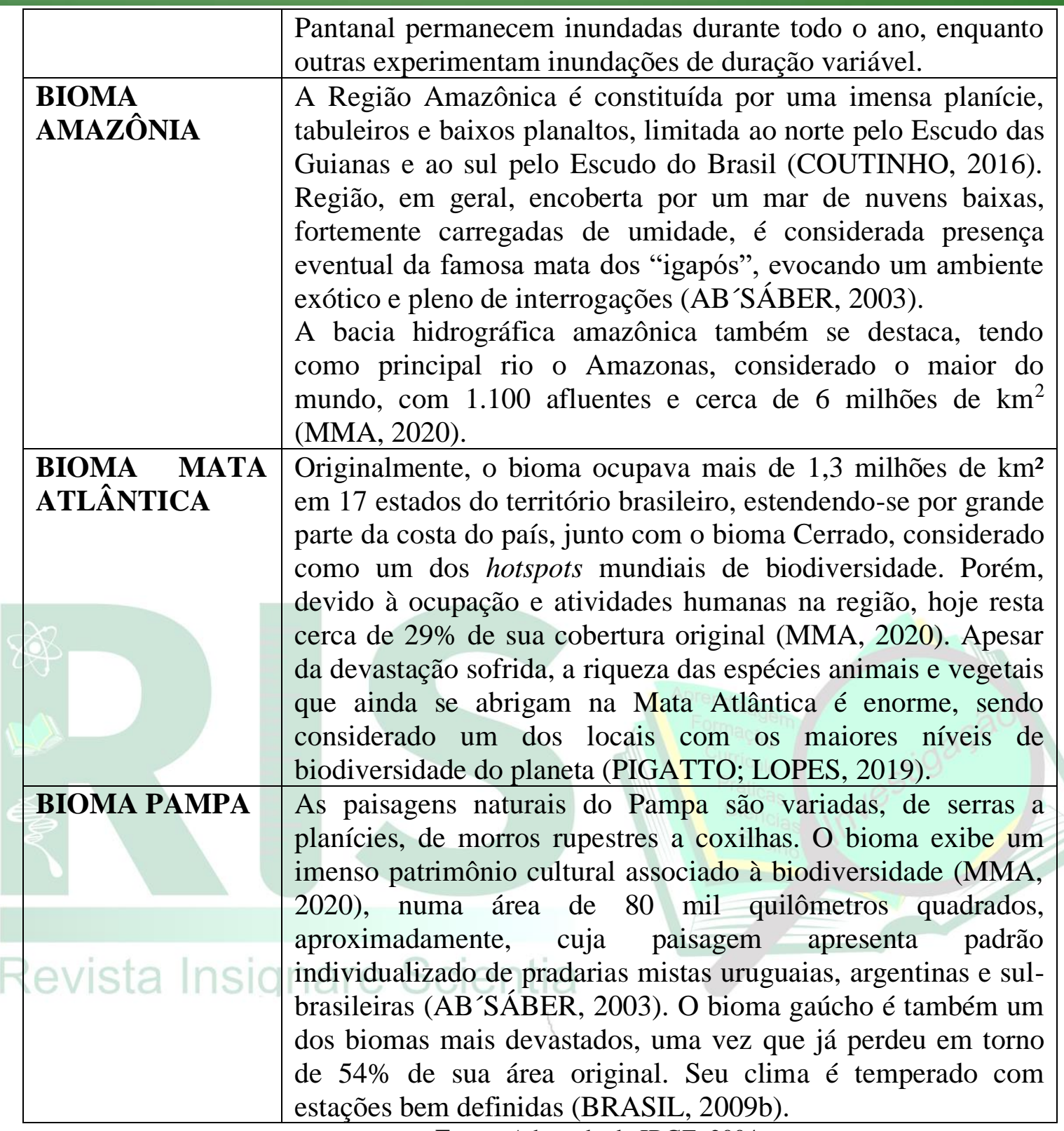

Fonte: Adaptado do IBGE, 2004

\section{METODOLOGIA}

Este estudo insere-se na Linha de Pesquisa Formação de Professores e Políticas de Educação em Ciências e Tecnologias, Programa de Pós-Graduação em Ensino Científico e Tecnológico (PPGEnCT), da Universidade Regional Integrada do Alto Uruguai e das Missões, campus de Santo Ângelo. No desenvolvimento da pesquisa, adotou-se uma abordagem mista por compreender coleta, análise e integração de dados quantitativos e qualitativos, visando a um maior entendimento do fenômeno investigado (CRESWELL; CLARK, 2013). Utilizou-se, como técnica, a pesquisa bibliográfica e documental, considerando-se que os materiais selecionados para análise foram as provas

Recebido em: 30/05/2021

Aceite em: 13/08/2021 
de Ciências da Natureza e suas Tecnologias do ENEM, período 2015-2019, disponíveis no portal do Instituto Nacional de Estudos e Pesquisas Educacionais Anísio Teixeira (INEP).

A prova de Ciências da Natureza e suas Tecnologias é composta por 45 questões objetivas, sendo 15 de Biologia, 15 de Química e 15 de Física. As questões por disciplina estão distribuídas, em sua grande maioria, de forma interdisciplinar, mas aleatória na prova, o que configura tarefa complexa para identificá-las.

$\mathrm{Na}$ primeira etapa da pesquisa, trabalhou-se no resgate das provas para identificação das questões de Biologia, que totalizaram 75 questões no período estudado. Em 2015, foram analisadas as questões do $1^{\circ}$ dia, no Caderno Azul; em 2016, no Caderno Rosa, também do $1^{\circ}$ dia; em 2017, no Caderno Amarelo, do $2^{\circ}$ dia; em 2018, no Caderno Azul, do $2^{\circ}$ dia; e, em 2019, no Caderno Cinza, do $2^{\circ}$ dia também.

Na segunda etapa, foi realizada a tabulação das questões de Biologia e a análise dos objetos de conhecimento na prova. Para isso, foi necessário separar as questões pelos objetos de conhecimento, de acordo com a Matriz de Referência ENEM, Ciências da Natureza e suas Tecnologias - Biologia, em: (i) Moléculas, células e tecidos; (ii) Hereditariedade e diversidade da vida; (iii) Identidade dos seres vivos; (iv) Ecologia e ciências ambientais; (v) Origem e evolução da vida; (vi) Qualidade de vida das populações humanas.

$\mathrm{Na}$ terceira etapa, foi realizado um levantamento das questões relacionadas ao objeto de conhecimento Ecologia e organizado um quadro que descreve os conteúdos que estão presentes na prova e os dados obtidos na pesquisa. Nessa etapa, foram identificadas as questões relativas aos biomas brasileiros.

Quanto à análise dos dados quantitativos, utilizou-se estatística descritiva simples, com cálculo de frequência e percentual. A análise qualitativa foi elaborada considerando-se as competências e habilidades relacionadas à Matriz de Referência para a prova de Ciências da Natureza e suas Tecnologias - Biologia, do ENEM (INEP, 2020). 


\section{RESULTADOS E ANÁLISE}

Os resultados são considerados em três seções complementares. Inicialmente, apresenta-se a análise geral das questões do ENEM com destaque para as questões de Biologia; na sequência, a análise das questões de Ecologia e, por último, a análise de duas questões relativas aos biomas.

\subsection{ANÁLISE GERAL DAS QUESTÕES DO ENEM}

No período analisado, foram identificadas 225 questões da área de Ciências da Natureza e suas Tecnologias, sendo 75 questões de Biologia, 75 questões de Física e 75 questões de Química. Entre as 75 de Biologia, cerca de $28 \%$ estão relacionadas aos conteúdos de Ecologia e, apenas, duas questões sobre biomas, uma relativa aos biomas brasileiros, e a outra, aos biomas mundiais. Isso representa menos de $3 \%$ da prova de Biologia.

Em uma primeira análise, as questões de Biologia foram mapeadas por objetos de conhecimento, de acordo com a Matriz de Referência ENEM Ciências da Natureza e suas Tecnologias - Biologia. Os dados obtidos encontram-se no Quadro 3.

Quadro 3: Relação dos objetos de conhecimento de Biologia nas provas do ENEM, 2015-2019

\begin{tabular}{|c|c|c|c|c|c|c|}
\hline Objetos de conhecimento & $\mathbf{2 0 1 5}$ & $\mathbf{2 0 1 6}$ & $\mathbf{2 0 1 7}$ & $\mathbf{2 0 1 8}$ & $\mathbf{2 0 1 9}$ & TOTAL \\
\hline Moléculas, células e tecidos & 5 & 4 & 5 & 4 & 4 & 22 \\
\hline $\begin{array}{c}\text { Hereditariedade e } \\
\text { diversidade da vida }\end{array}$ & 2 & 2 & 3 & 2 & 2 & 11 \\
\hline Identidade dos seres vivos & 6 & 2 & 3 & 4 & 5 & 20 \\
\hline $\begin{array}{c}\text { Ecologia e ciências } \\
\text { ambientais }\end{array}$ & 2 & 6 & 4 & 5 & 4 & 21 \\
\hline Origem e evolução da vida & - & 1 & - & - & - & 01 \\
\hline $\begin{array}{c}\text { Qualidade de vida das } \\
\text { populações humanas }\end{array}$ & - & - & - & - & - & - \\
\hline
\end{tabular}

Fonte: Autoras

Como se observa no Quadro 3, as provas de Biologia, do ENEM, no período analisado, priorizaram questões relativas a moléculas, células e tecidos, ecologia e ciências ambientais e, em terceiro lugar, questões sobre a identidade dos seres vivos. Uma observação importante diz respeito à origem e evolução da vida, tendo em vista que se identificou apenas uma questão sobre esse objeto do conhecimento, na prova de

Recebido em: 30/05/2021

Aceite em: 13/08/2021 
2016. Isso pode indicar que, para o ENEM, o ensino dessa temática não apresenta grande relevância.

A frequência dos objetos de conhecimento, contemplados nas provas de Biologia, encontra-se representada no gráfico a seguir, Figura 2.

Figura 2. Gráfico de frequência dos objetos de conhecimento em Biologia, nas Provas de Ciências da Natureza, do Enem, aplicadas no período de 2015 a 2019.

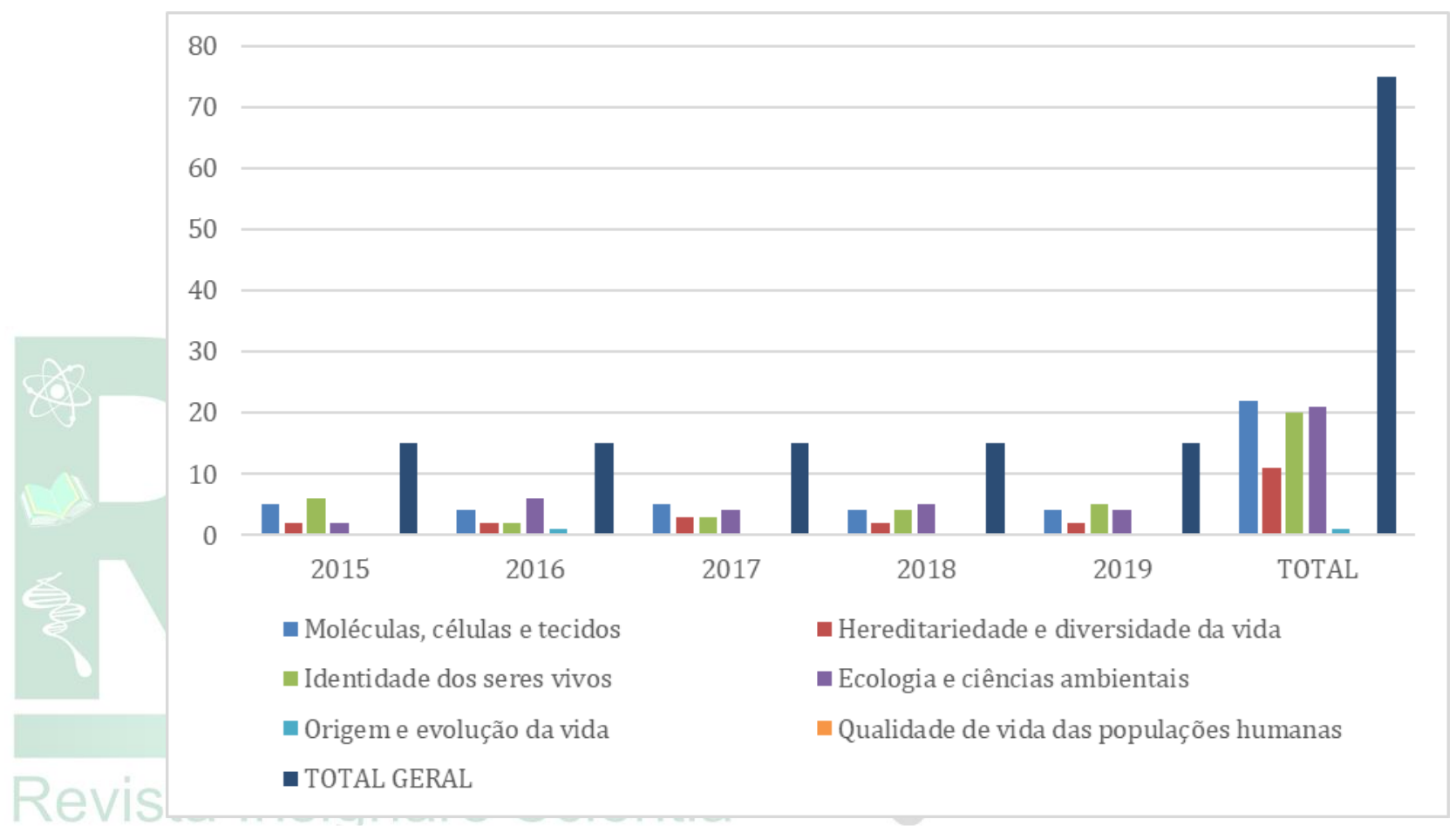

Fonte: As autoras.

O objeto de conhecimento "qualidade de vida nas populações humanas" não foi contemplado em nenhuma prova dos últimos cinco anos. Então, poder-se-ia questionar por que razões continuar trabalhando conteúdos no Ensino Médio que não são relevantes para a preparação do aluno ao ENEM?

Por outro lado, um estudo realizado por Silva, Rabelo e Canhoto (2020) aponta que $78 \%$ dos professores de Biologia que participaram da pesquisa responderam que utilizaram as questões do ENEM em sala de aula, como método de ensino para preparar os alunos a participarem do exame. Isso mostra que o ENEM é referência ao planejamento das aulas de um número considerável de professores de Biologia. Mesmo assim, é necessário destacar que a finalidade do ensino de Ciências e Biologia é muito mais relevante do que apenas preparar o estudante para lograr sucesso em testes de Recebido em: 30/05/2021 
avaliação externa. A educação científica e tecnológica deverá proporcionar a formação, a inserção e o desenvolvimento da capacidade criativa do cidadão na sociedade, isto é, deverá dotar o indivíduo de condição para utilizar os saberes das disciplinas, para que ele possa enfrentar, com sucesso, as situações da existência (SCHEID, 2018). Nessa direção, os conteúdos do objeto de conhecimento acima mencionado são fundamentais.

\subsection{ANÁLISE DAS QUESTÕES DE ECOLOGIA}

Num segundo momento, procedeu-se à análise dos conteúdos de Ecologia contemplados nas vinte e uma (21) questões identificadas no período do estudo. Esses dados encontram-se no Quadro 4, a seguir.

Quadro 4: Relação dos conceitos de Ecologia nas provas do ENEM, 2015-2019.

\begin{tabular}{|c|c|c|c|c|c|c|}
\hline $\begin{array}{c}\text { Conteúdos de } \\
\text { Ecologia }\end{array}$ & $\mathbf{2 0 1 5}$ & $\mathbf{2 0 1 6}$ & $\mathbf{2 0 1 7}$ & $\mathbf{2 0 1 8}$ & $\mathbf{2 0 1 9}$ & TOTAL \\
\hline Sucessão ecológica & & 1 & & & 1 & 02 \\
\hline Biomas Brasileiros & & 1 & & & & 01 \\
\hline Biomas Mundiais & & & & 1 & & 01 \\
\hline Cadeias e teias & & 1 & 1 & & & 02 \\
\hline alimentares & & & & & & 02 \\
\hline ambiente Poluição e meio & & 1 & 1 & 1 & & 05 \\
\hline Ciclos & & 1 & 1 & 1 & 1 & 02 \\
\hline biogeoquímicos & 1 & 1 & & & & \\
\hline Relações ecológicas & & 1 & 2 & 1 & 2 & 06 \\
\hline Ações antrópicas & 1 & & & & & \\
\hline
\end{tabular}

Fonte: Autoras

De acordo com os dados levantados, é possível observar que os conceitos de Ecologia, presentes na Prova de Ciências da Natureza e suas Tecnologias - Biologia, do ENEM, no período de 2015-2019, dizem respeito a relações ecológicas e ciclos biogeoquímicos, conforme gráfico representado na Figura 3.

Figura 3. Gráfico de frequência dos conceitos abordados em Ecologia e Ciências Ambientais, na Prova de Ciências da Natureza, do Enem, aplicadas no período de 2015 a 2019.

Recebido em: 30/05/2021

Aceite em: 13/08/2021 
5

0

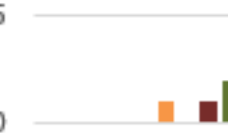

2015

2016

2017

2018

2019

TOTAL

- Sucessão ecológica

- Biomas Brasileiros

" Biomas Mundiais

n Cadeias e teias alimentares $\mathbf{~ P o l u i c ̧ a ̃ o ~ e ~ m e i o ~ a m b i e n t e ~}$

- Relações ecológicas

- Ações antrópicas

- TOTAL GERAL

Fonte: As autoras.

Após a identificação dos conteúdos de Ecologia nas provas dos últimos cinco anos, observou-se que as "relações ecológicas entre os seres vivos" são as mais frequentes, correspondendo a $28 \%$ das questões, seguidas dos ciclos biogeoquímicos. Por outro lado, foi possível constatar que somente houve uma (1) questão sobre os biomas brasileiros, na prova de 2016, e uma questão sobre biomas mundiais, na prova de 2018. Isso significa que, apesar da importância dos biomas para o desenvolvimento e manutenção das diferentes espécies animais e vegetais e para o equilíbrio do planeta, esse conteúdo é pouco valorizado nas provas do ENEM. Com isso, evidencia-se a valorização de conteúdos isolados, como as "relações ecológicas" ou os "ciclos biogeoquímicos. Por conta disso, infere-se que, subjacente às provas do ENEM, persiste uma concepção de ensino e de ciência fragmentária que separa o que, por natureza, foi tecido junto. A rigor, esta é uma visão contraditória à própria Ecologia como ciência das relações, pois “o ambiente não é fragmentado e todos os componentes de um ecossistema interagem entre si de maneira complexa" (PERTICARRARI et al., 2010, p. 270).

\subsection{ANÁLISE DAS QUESTÕES SOBRE BIOMAS}

Nesta seção, são analisadas as duas questões relativas a biomas nas provas do ENEM, no período de 2015-2019. A análise toma como referência as Competências e

Recebido em: 30/05/2021

Aceite em: 13/08/2021 
Habilidades que constam na matriz de referência na área de Ciências da Natureza e suas

Tecnologias, do INEP. A seguir, na Figura 4, apresenta-se a primeira questão analisada.

\section{QUESTÃO 87}

A vegetação apresenta adaptaçōes ao ambiente, como plantas arbóreas e arbustivas com raizes que se expandem horizontalmente, permitindo forte ancoragem no substrato lamacento; raízes que se expandem verticalmente, por causa da baixa oxigenação do substrato; folhas que têm glândulas para eliminar o excesso de sais; folhas que podem apresentar cutícula espessa para reduzir a perda de água por evaporação.

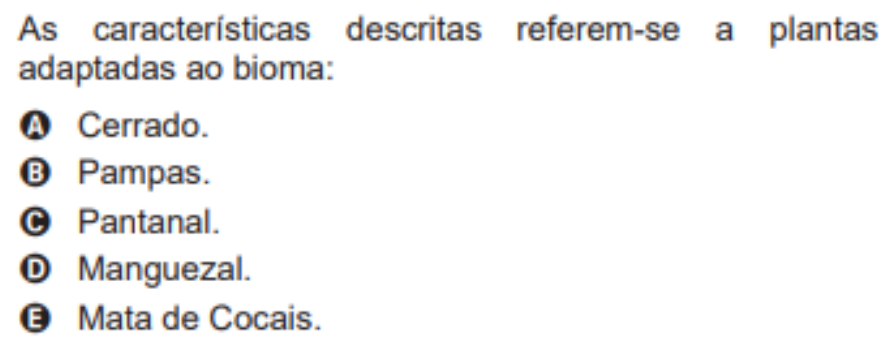

Figura 4 - Questão Número 87 da prova do ENEM, área de Ciências da Natureza e suas Tecnologias, no ano de 2016. (1 ${ }^{\circ}$ dia | Caderno 4 - ROSA - p. 31)

A primeira questão sobre os biomas brasileiros, aplicada na prova 2016, exige que o aluno conheça, conforme apresentado na Figura 4, a Competência da área 8 Apropriar-se de conhecimentos da Biologia para, em situações-problema, interpretar, avaliar ou planejar intervenções científico-tecnológicas; e a Habilidade 28 - Associar características adaptativas dos organismos com seu modo de vida ou com seus limites de distribuição em diferentes ambientes, em especial, em ambientes brasileiros.

Para acertar essa questão, o estudante deveria conhecer os ecossistemas que compõem os biomas brasileiros, tendo em vista que a questão se refere ao ecossistema manguezal (alternativa D), que faz parte do bioma Mata Atlântica. Também, precisaria ter conhecimento de anatomia e fisiologia vegetal para reconhecer as características descritas no texto. Esses conhecimentos são desenvolvidos durante a educação básica, por meio do estudo dos ecossistemas, quando se estudam os biomas brasileiros. Segundo Santos et al. (2020, p. 409), "o ensino de Biologia passa ser uma ação que nos possibilitará refazer e reconstruir sociedades, assim como estabelecer uma relação harmoniosa para com as pessoas e, também, para com outros seres vivos". Observa-se que esses autores reafirmam a importância do ensino de Biologia para a compreensão

Recebido em: 30/05/2021

Aceite em: 13/08/2021 
das relações harmoniosas entre os seres vivos, incluindo a espécie humana. Na Figura

5, apresenta-se a segunda questão do ENEM, aqui, analisada.

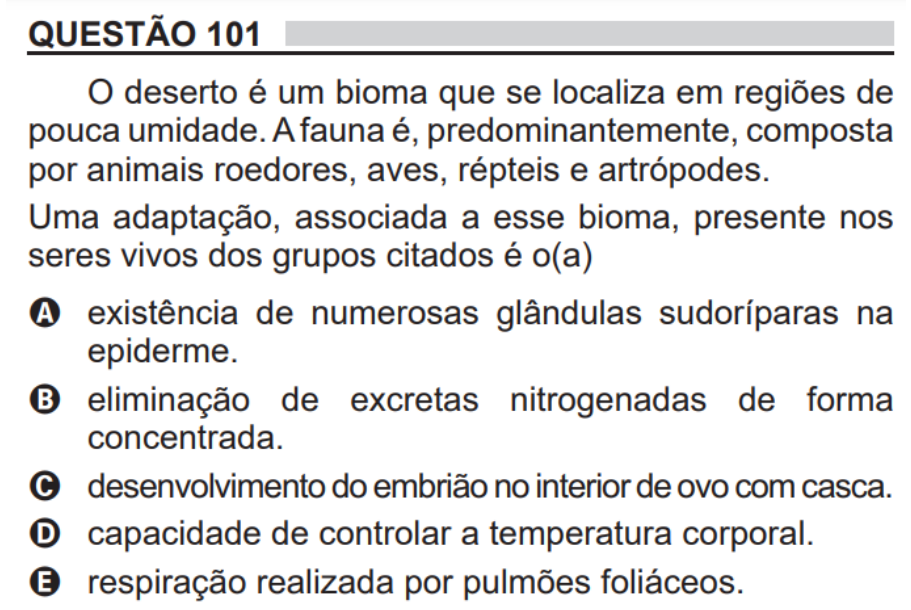

Figura 5 - Questão Número 101 da prova do ENEM, área de Ciências da Natureza e suas Tecnologias, no ano de 2018. ( $2^{\circ}$ dia | Caderno 7 - AZUL - p. 05)

A segunda questão relativa a biomas, encontrada na prova de 2018 (Fig. 5), exigiu a competência da área de número 4: "Compreender interações entre organismos e ambiente, em particular aquelas relacionadas à saúde humana, relacionando conhecimentos científicos, aspectos culturais e características individuais, e as Habilidades H13 e H14, respectivamente: "Reconhecer mecanismos de transmissão da vida, prevendo ou explicando a manifestação de características dos seres vivos" e "Identificar padrões em fenômenos e processos vitais dos organismos, como manutenção do equilíbrio interno, defesa, relações com o ambiente, sexualidade, entre outros".

Apesar de o enunciado da questão referir-se a um bioma mundial (o deserto), a resposta está relacionada ao sistema urinário e a tipos de excreções nos animais, pois a resposta correta é a alternativa B. Para acertar essa questão, o estudante necessitava de conhecimentos específicos sobre o bioma deserto e sobre a fisiologia do sistema excretor dos animais citados na questão. Para viver em um ambiente inóspito como o deserto, esses animais precisam economizar água, isso ocorre através da diminuição da perda de água por suas excretas nitrogenadas, principalmente com urina mais concentrada, evitando a perda de água. 
Observa-se que as competências e habilidades exigidas, nas duas questões analisadas, estão de acordo com a BNCC para a área das Ciências da Natureza, promovendo integração entre os componentes de Física, Química e Biologia, por meio da organização de competências e habilidades essenciais, desenvolvidas necessariamente nos estudantes durante sua formação. Ainda, o estudo dos biomas brasileiros no Ensino Médio é essencial para que o estudante consiga compreender a importância dos demais conceitos trabalhados em Ecologia, conseguindo, com isso, identificar os seis grandes biomas brasileiros, sua localização, inserção, características de fauna e flora e seus principais problemas ambientais. Isso está de acordo com os seguintes argumentos de Silva e Coutinho (2018, p. 04), “estudar as características dos biomas é necessário no sentido de perceber a sua importância para a manutenção da vida na Terra".

Como o estudante conseguirá entender quais as competências necessárias para resolver situações-problema, argumentar e analisar os fenômenos da natureza na prova do ENEM se lhe faltam as habilidades mínimas de conhecimento sobre ecossistemas, biodiversidade e preservação da vida em todas as suas formas? Infere-se que, se a temática biomas brasileiros não retornar com a ênfase merecida na prova do ENEM, provavelmente, em pouco tempo, poderá deixar de ser abordada na Educação Básica. Para a maioria dos estudantes, é difícil relacionar os conceitos de Ecologia sem entender o conceito de bioma e sua importância, porque, muitas vezes, até os livros didáticos não apresentam consenso sobre esse conceito.

\section{CONSIDERAÇÕES FINAIS}

Com a análise das questões da prova de Ciências da Natureza e suas Tecnologias - Biologia, do ENEM, aplicadas no período de 2015-2019, foi possível observar que a temática sobre biomas brasileiros não vem recebendo, em nosso entendimento, a devida atenção no exame.

Constatou-se que os conhecimentos de Ecologia são priorizados nas provas analisadas, porém questões relacionadas aos biomas brasileiros são praticamente inexistentes, o que gera a compreensão de que esse tema é pouco relevante à prova do ENEM e o que, seguramente, poderá interferir no ensino escolar de Biologia, tendo em vista que os conteúdos priorizados, nas provas, constituem-se em uma referência ao 
planejamento dos professores. É importante mencionar que o aprofundamento do conteúdo sobre os biomas brasileiros é fundamental para a formação de cidadãos comprometidos com o enfrentamento de problemas socioambientais, cruciais para a sobrevivência de todos os seres do planeta.

Espera-se que a implementação da Base Nacional Comum Curricular, em todas as escolas, possibilite aos estudantes apropriação dos conhecimentos nos mais diversos campos das Ciências da Natureza de maneira integrada. Assim, ao chegar ao final da Educação Básica, os alunos devem ter se apropriado dos conhecimentos necessários para identificar e resolver situações do seu cotidiano, inclusive, as apresentadas no Exame Nacional do Ensino Médio.

\section{REFERÊNCIAS}

AB'SÁBER, A. N. Os domínios de natureza no Brasil: potencialidades paisagísticas. São Paulo, Ateliê Editorial, 2003.

ALEIXO, A. et al. Mudanças climáticas e a biodiversidade dos biomas Brasileiros: passado, presente e futuro. Natureza \& Conservação, 2010. p. 194-196. Disponível em: Natureza \& Conservação 8(2) 2010 Aleixo.pdf. Acesso em: 12 jan. 2021.

ASSINE, M. L. et al. Anatomia funcional da paisagem: a diversidade física do Pantanal e as inundações. Ciência Pantanal, v.4. n.1, p. 12-20, 2018. Disponível em:

https://d3nehc6yl9qzo4.cloudfront.net/downloads/revista_ciencia_pantanal_1.pdf. Acesso em: 20 jan. 2021.

BEZERRA, R.G.; SUESS, R.C. Abordagem do Bioma Cerrado em Livros Didáticos de Biologia do Ensino Médio. Holos, ano, 29, v. 1, p. 233-242, 2013. Disponível em: http://www2.ifrn.edu.br/ojs/index.php/HOLOS/article/view/1289/653. Acesso em: 06 jan. 2021.

BRASIL. Base Nacional Comum Curricular. Ensino Médio. Brasília: MEC. 2018. Disponível em: http://basenacionalcomum.mec.gov.br/. Acesso em: 06 jan. 2021.

BRASIL. Ministério da Educação. Instituto Nacional de Estudos e Pesquisas Educacionais Anísio Teixeira. Enem: documento básico. Brasília, 1998.

BRASIL. Instituto Nacional de Estudos e Pesquisas Educacionais Anísio Teixeira. Enem: documento básico. Brasília, 2000.

BRASIL. Instituto Nacional de Estudos e Pesquisas Educacionais Anísio Teixeira. Enem: relatório. Brasília, 2001. 
BRASIL. Ministério da Educação. Portaria MEC 462. 2009a. Disponível em: http://siau.edunet.sp.gov.br/ItemLise/arquivos/notas/portmec462_09.htm. Acesso em: 12 jan. 2021.

BRASIL, Ministério da Educação e Instituto Nacional de Estudos e Pesquisas Educacionais Anísio Teixeira. Matriz de Referência para o ENEM 2009. Brasília, Distrito Federal, 2009b. 24p. Disponível em:

file:///C:/Users/User/Downloads/matriz_referencia.pdf. Acesso em: 21 dez. 2020.

CASTRO, L. R. B. et al. Os biomas brasileiros nos livros didáticos de ciências: um olhar ao Pampa Gaúcho. Revista Electrónica de Investigación en Educación en Ciências, Argentina, 2019. v. 14, n. 1, p. 38-49. Disponível em: file:///C:/Users/User/Desktop/13942-45454575771979-1-PB.pdf. Acesso em: 7 nov. 2020.

COUTINHO; L. M. Biomas brasileiros. São Paulo. Oficina de Textos, 2016.

CRESWELL, J. W. ; CLARK, V. L. Pesquisa de métodos mistos. 2. ed. Porto Alegre: Penso, 2013.

GOMES, C. M. A. Avaliando a avaliação escolar: notas escolares e inteligência fluida. Psicologia em Estudo, v.15, n.4, p.841-849, 2010.

ILHÉU, T. Guia do Estudante. Quais os assuntos de Biologia mais cobrados no Enem. Editora Abril. Atualizado em 12 set. 2019. Disponível em:

https://guiadoestudante.abril.com.br/estudo/quais-os-assuntos-de-biologia-maiscobrados-no-enem/. Acesso em: 08 jan. 2021.

INSTITUTO BRASILEIRO DE GEOGRAFIA E ESTATÍSTICA (IBGE). Mapa de biomas e de vegetação. 2004. Disponível em:

https://https://www.ibge.gov.br/apps/biomas/html. Acesso em: 14 jan. 2021.

INSTITUTO NACIONAL DE ESTUDOS E PESQUISAS EDUCACIONAIS ANÍSIO TEIXEIRA (INEP). Exame Nacional do Ensino Médio - ENEM 2015; 2016; 2017; 2018; 2019. Ministério da Educação. Disponível em:

http://portal.inep.gov.br/web/guest/provas-e-gabaritos. Acesso em: 09 dez. 2020.

LEOPOLDO, L.; BASTOS, F. A pesquisa em Ensino de Botânica: contribuições e características da produção científica em periódicos. Revista Insignare Scientia - RIS, v. 1, n. 3, p. 1-21, 2018. Disponível em:

https://periodicos.uffs.edu.br/index.php/RIS/article/view/8267. Acesso em: 12 fev.2021.

MALIMPENSA, G. C.; RINK, J. Conteúdos de Genética nas provas do ENEM: uma análise de dez anos de exame (2005-2014). Avaliação e Educação em Ciências, v.1, n.3, p.1-9, 2017.

Recebido em: 30/05/2021

Aceite em: 13/08/2021 
MINISTÉRIO DO MEIO AMBIENTE (MMA). Biomas. Amazônia; Caatinga;

Cerrado; Mata Atlântica; Pampa; Pantanal. 2020. Disponível em:

https://antigo.mma.gov.br/biomas.html. Acesso em: 20 jan. 2021.

MYERS, N. Threatened biotas: "Hot spots" in tropical forests. Environmentalist, n. 8, p. 187-208, 1988.

PERTICARRARI, A. et al. O uso de textos de divulgação científica para o ensino de conceitos sobre ecologia a estudantes da educação básica. Ciênc. educ.(Bauru), Bauru, v.16, n.2, p.369-386, 2010. Disponível em: http://dx.doi.org/10.1590/S151673132010000200007. Acesso em: 05 fev. 2021.

PIGATTO, A. G.S.; LOPES, M. P. A classificação dos Biomas Brasileiros em livros didáticos de Biologia. Atlante: Cuadernos de Educación y Desarrollo. 2019. Disponível em: https://www.eumed.net/rev/atlante/2019/07/livros-didaticosbiologia.html. Acesso em: 20 jan. 2021.

SANTOS F. M. et al.; Ensino de Biologia com enfoque CTSA: uma abordagem sobre Educação Ambiental e Sustentabilidade no Ensino Médio da rede pública do Estado do Ceará. Revista Insignare Scientia - RIS, v. 3, n. 2, p. 406-427, 2020. Disponível em: https://periodicos.uffs.edu.br/index.php/RIS/issue/view/111. Acesso em: 15. fev. 2021.

SCHEID, N. M. J. História da ciência na educação científica e tecnológica: contribuições e desafios. Revista Brasileira de Ensino Ciências e Tecnologia. Ponta Grossa, v. 11, n. 2, p. 443-458, maio/ago. 2018.

SILVA, R. C.; COUTINHO, S. F. S. Biomas nordestinos: um estudo no âmbito da mata atlântica e da caatinga. In: CONGRESSO NACIONAL DE EDUCAÇÃO, 4., 2018. Anais [...]. Recife, PE: Editora Realize, 2018.

SILVA. D.; REBELO, M. V.; CANHOTO, C. M. Percepções dos professores de biologia sobre a avaliação em larga escala em Portugal e Brasil. Educação, v. 45, 2020. Disponível em:https://periodicos.ufsm.br/reveducacao/article/view/39560. Acesso em: 12 dez. 2020.

XAVIER, R. P.; SOUZA, D. T. O que os pensam sobre o livro didático de inglês? Trab. Ling. Aplic., Campinas, v. 47, n. 1, p. 65-89, jan./jun. 2008.

ZANCHET, B. M. B. A. O Exame Nacional do Ensino Médio - ENEM: uma auto avaliação para quem? Avaliação: Revista da Avaliação da Educação Superior. Campinas, v. 8, n. 3, p. 247-269, 2003.

Recebido em: 30/05/2021

Aceite em: 13/08/2021 